\title{
Are Australian regulatory codes adequate in scope to protect youth from alcohol advertising?
}

Michelle I Jongenelis, Hannah Pierce, Danica Keric, Julia Stafford, Gregory Jongenelis, and Simone Pettigrew

Dr Michelle Jongenelis (ORCID: 0000-0002-0717-1692)

Melbourne Centre for Behaviour Change

Melbourne School of Psychological Sciences, University of Melbourne

Ms Hannah Pierce (ORCID: 0000-0003-1477-0340)

Public Health Advocacy Institute of Western Australia, Curtin University

Cancer Council Western Australia

Ms Danica Keric

Public Health Advocacy Institute of Western Australia, Curtin University

Cancer Council Western Australia

Ms Julia Stafford (ORCID: 0000-0001-5959-0525)

Public Health Advocacy Institute of Western Australia, Curtin University

Cancer Council Western Australia

Mr Gregory Jongenelis

School of Psychology, Curtin University

Professor Simone Pettigrew (ORCID: 0000-0003-3921-1174)

The George Institute for Global Health

This is the author manuscript accepted for publication and has undergone full peer review but has not been through the copyediting, typesetting, pagination and proofreading process, which may lead to differences between this version and the Version of Record. Please cite this article as doi: $\underline{10.1002 / \text { HPJA.410 }}$

This article is protected by copyright. All rights reserved 
Corresponding author:

Michelle I Jongenelis (PhD)

Senior Research Fellow

Melbourne Centre for Behaviour Change, Melbourne School of Psychological Sciences

The University of Melbourne

Parkville, Victoria, 3010

E: Michelle.jongenelis@unimelb.edu.au

P: +610390354979

Running title: Australian Alcohol Advertising Codes

Funding statement: N/A

Acknowledgments statement: N/A

Conflict of interest: Author MJ is a panel member for the Alcohol Advertising Review Board; authors HP, DK, and JS are involved in the administration of the Board; and author SP is a member of the Board's Steering Committee.

Keywords: alcohol advertising; regulation; Alcohol Advertising Review Board; Alcohol Beverages Advertising Code; youth.

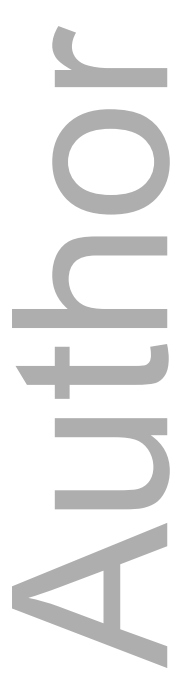


DR MICHELLE I JONGENELIS (Orcid ID : 0000-0002-0717-1692)
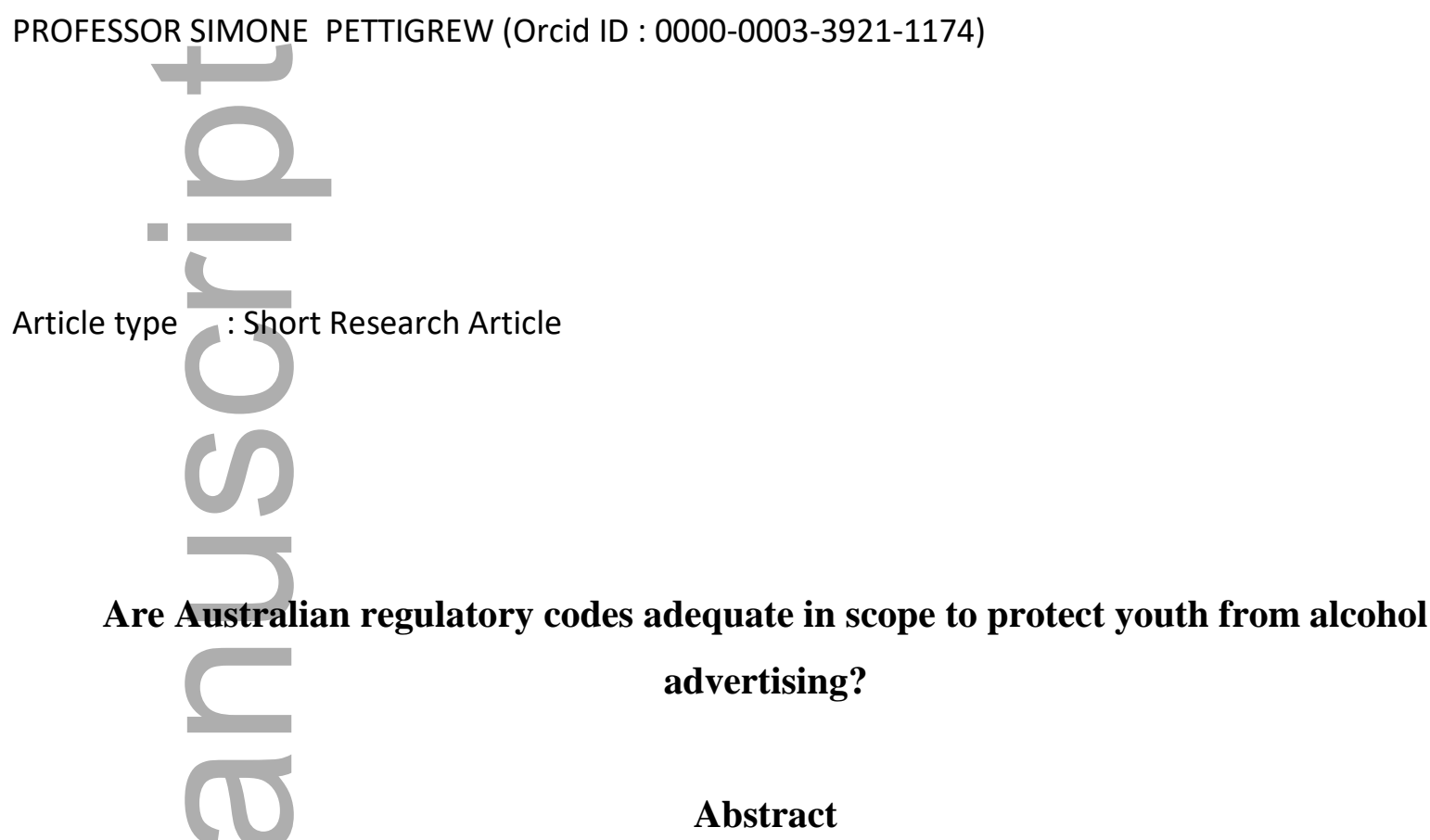

Abstract

Issue addressed: Exposure to alcohol advertising has been found to be associated with more positive attitudes toward alcohol and heavier drinking among youth. Appropriate regulation of alcohol advertising is thus crucial for reducing use among members of this population group. To assist policy makers in their alcohol control efforts, this study explored the scope of Australian alcohol advertising codes and the extent to which they address issues relating to youth exposure. Methods: Two researchers assessed 628 unique alcohol advertisements against youth-related provisions of the Alcohol Advertising Review Board (AARB) Code and Alcohol Beverages Advertising Code (ABAC). A third researcher resolved discrepancies. The ads sampled were those that had been the subject of formal complaints to the AARB.

Results: Most (94\%) ads were assessed as violating at least one of the AARB Code provisions relating to youth, while $36 \%$ were found to violate at least one of the ABAC youth provisions. The most frequently violated AARB Code provision related to placement, with $88 \%$ of ads located in places or broadcast at times where young people were likely to be exposed. The most frequently violated $\mathrm{ABAC}$ provision related to appeal to minors (33\%). 
Conclusions: Results indicate that self-regulation is an ineffective means of protecting youth from alcohol advertising, with the ABAC failing to capture many ads featuring content that appeals to youth.

So What? Greater efforts are required to protect youth from alcohol advertising. Findings from the present study reinforce calls for mandatory, evidence-based regulation that is administered independently of the alcohol industry.

Summary: An analysis of 628 unique alcohol advertisements found that the vast majority were in violation of the AARB Code's youth-related provisions whereas substantially fewer were in violation of the ABAC, supporting arguments that self-regulation is an ineffective means of protecting youth from alcohol advertising.

Keywords: alcohol advertising; regulation; Alcohol Advertising Review Board; Alcohol Beverages Advertising Code; youth.

\section{Introduction}

Alcohol consumption is a leading risk factor for mortality and poor health worldwide ${ }^{1}$, with strong evidence documenting the association between consumption and a range of acute and chronic harms ${ }^{2}$. In Australia, the context of the present study, alcohol use has been found to contribute to $4.5 \%$ of the nation's disease and injury burden ${ }^{3}$. The resulting impact on the Australian economy is substantial: the overall cost of excessive alcohol consumption has been conservatively estimated at $\$ 36$ billion annually, which includes costs associated with alcoholrelated traffic accidents, health care, workplace absenteeism, and lost workplace productivity ${ }^{4}$ Reductions in alcohol consumption levels thus have the potential to minimise alcohol-related harm and reduce the economic costs associated with alcohol use.

Although the last decade has seen a decline in per-capita alcohol consumption among Australians ${ }^{5}$, overall consumption rates remain unacceptably high. Recent figures from the Australian Institute of Health and Welfare indicate that $25 \%$ of people aged $14+$ years consume alcohol at levels associated with single occasion risk ${ }^{6}$, defined as the consumption of more than four standard drinks on one occasion at least once a month ${ }^{7}$. Those aged 18 to 24 years are the riskiest drinkers, with $41 \%$ consuming alcohol at levels associated with single occasion risk at least once a month ${ }^{6}$. Efforts are thus urgently needed to reduce population-level consumption of 
alcohol to minimise the negative impacts of this harmful commodity. Such efforts are especially needed among children, adolescents, and young adults given the serious harms that have been associated with alcohol consumption among members of these population groups (e.g., blackouts, accidental injury, and suboptimal brain development $)^{8-10}$.

r

Among adolescents and young adults, exposure to alcohol advertising has been found to be associated with more positive attitudes toward alcohol, increased alcohol consumption, heavier drinking, underage drinking, and earlier initiation of alcohol use ${ }^{11-15}$. This is likely due to the unique developmental stage of adolescence and young adulthood, a period characterised by poor inhibitory control and neurobiological susceptibility to impulsivity, sensation seeking, sensitisation to reward cues, and risk-taking behaviour ${ }^{16-19}$. Appropriate regulation of alcohol advertising is therefore crucial for reducing alcohol use, with the restriction or banning of alcohol advertising constituting one of the three 'best buys' recommended by the World Health Organization 20 .

In Australia there are two voluntary advertising codes that provide guidelines for the marketing of alcohol products: the Alcohol Beverages Advertising Code (ABAC) and the Alcohol Advertising Review Board (AARB) Code. The ABAC, developed in 1998, is managed by the alcohol industry and has been criticised for being limited in scope and containing significant loopholes ${ }^{21-23}$. In recognition of the compelling need for comprehensive and effective regulation of alcohol advertising in Australia, the AARB was established in March 2012 by public health groups as an alternate system of alcohol advertising review. During a comprehensive development phase, a steering committee comprising representatives from various health organisations produced a Code that covered all forms of alcohol marketing and contained provisions that related to protecting children and young people ${ }^{22,24}$. Existing provisions from self-regulatory codes in Australia, New Zealand, the UK, and Canada were used to create the AARB content code. As there were few existing codes that could be used to inform development of the AARB placement code, the steering committee created a set of placement provisions that would reduce children's exposure to alcohol advertising, guided by the recommendation made by the National Preventative Health Taskforce to "phase out alcohol promotions from times and placements which have high exposure to young people aged up to 25 years" 25 . 
This result of this development phase was a code that is substantially more comprehensive than the ABAC, especially in relation to protecting youth from exposure to alcohol marketing and appealing alcohol-related content. For example, the AARB contains 44 provisions (with 17 relating specifically to youth), while the ABAC contains only 12 (with just three youth-specific provisions). In addition, given brain development continues in young adulthood and is not fully complete until roughly 25 years of age ${ }^{26}$, the AARB Code aims to minimise exposure to advertising among 'young people', which it defines as those aged less than 25 years. By contrast, the ABAC uses the term 'minor' in its provisions, which it defines as those younger than 18 years. To ensure the provision of an alcohol advertising review service that is impartial and unencumbered by vested interests, the AARB Code is administered independently of the alcohol industry. As a result, however, it is not endorsed by the industry.

\section{Present Study}

The appropriate regulation of alcohol advertising constitutes a potential means of reducing alcohol use among youth ${ }^{27}$. To determine the extent to which Australia's existing regulatory codes may require strengthening to better protect youth from alcohol advertising, the present study examined the scope of these codes and the extent to which they capture problematic alcohol advertisements by assessing a sample of advertisements that had been the subject of formal complaints to the AARB. Results may assist policy makers in their alcohol control efforts by identifying potential improvements to existing codes.

\section{Advertisements}

\section{Method}

A unique database of alcohol advertisements that were the subject of formal complaints submitted to the AARB from March 2012 to March 2017 was accessed. This database is compiled and managed by the Public Health Advocacy Institute of Western Australia and Cancer Council Western Australia. Permission was sought from and granted by the two organisations to use this database for research purposes. 
Complaints related to 668 unique alcohol ads, of which 628 could be located and thus subject to content analysis. The remaining 40 ads were unavailable for review as they were no longer accessible. All ads were accompanied by meta data relating to the location of the ad and the time the ad was viewed by the complainant. All accessible ads were subject to analysis, regardless of whether the complaint to which it related was upheld by the AARB.

\section{Coding Protocol}

The ads were initially assessed by two researchers (XX and XX). Prior to commencing coding, the researchers familiarised themselves with both the AARB Code (available at https://alcohol.phaiwa.org.au/alcohol-advertising-review-board/about-aarb) and the ABAC (available at http://www.abac.org.au/publications/thecode/). They then discussed each of the

provisions within the codes to ensure they had a shared understanding of the operationalisation of each. When reviewing complaints under the ABAC, assessors are asked to consider how a 'reasonable' person would interpret the communication, based upon the "values, opinions and life experiences found commonly in a majority of the community" 28 . The researchers took a similar approach to coding the ads in this study, with consideration given to the nature of the advertised product, the medium used, and those likely to be exposed to the ad. They then jointly coded the first 20 ads. Any discrepancies were discussed until consensus was reached. The remaining ads were then coded independently. Inter-rater reliability was $96 \%$ for violations to the AARB Code and $96 \%$ for violations to the ABAC. A third researcher, XX, resolved discrepancies in consultation with the other two researchers.

Those provisions relating specifically to youth/young people (for the AARB Code) and minors (for the ABAC) were the focus of the present study. The results that follow relate to these 17 AARB Code and 3 ABAC provisions.

\section{Results}

\section{Violations: Overall}

Ninety-four percent of ads in the sample violated at least one AARB Code provision relating to youth, while $36 \%$ violated at least one ABAC youth-related provision. On average, the ads in the 
sample each violated three youth-related provisions from the AARB Code but less than one (0.41) from the ABAC (see Table 1).

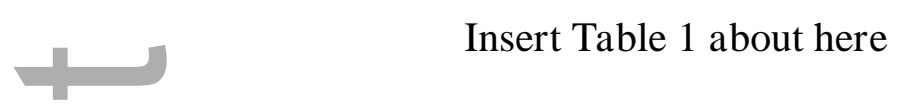

\section{Violations: Specific}

Table 2 presents the specific AARB Code and ABAC provisions relating to youth and the number of ads violating each. The most frequently violated AARB Code provision related to ad placement, with $88 \%$ of the ads located in places or broadcast at times where young people are exposed or are likely to be exposed. The next most frequently violated AARB Code provision related to content, with nearly half of all ads (48\%) deemed to be directed at or have strong or evident appeal to young people (e.g., they used elements known to appeal to youth such as cartoon characters and/or animals, humour, or camaraderie $\left.{ }^{29,30}\right)$.

One-third of the ads were assessed as being likely to appeal to minors and thus violated the relevant $\mathrm{ABAC}$ provision. The next most frequently violated $\mathrm{ABAC}$ provision related to the depiction of an adult who is under 25 years of age (8\%).

\section{Insert Table 2 about here}

\section{Discussion}

To assist policy makers in their alcohol control efforts, the present study examined the scope of Australian alcohol advertising codes and the extent to which they address issues relating to youth appeal and exposure. The majority (94\%) of the assessed ads were deemed to be in violation of the AARB Code's youth-related provisions and a substantial minority (36\%) were in violation of the ABAC.

Supporting criticisms that the wording of the ABAC is inadequate in scope and fails to capture many problematic alcohol ads ${ }^{21-23}$, many more ads were deemed to be in violation of the AARB Code provision relating to the appeal of ads to youth compared to the ABAC provision relating to the appeal of ads to minors (48\% vs. $33 \%$ ). This discrepancy is most likely attributable to the 
differing definitions used in the codes, with the AARB Code defining youth as those aged less than 25 years and the ABAC defining minors as those younger than 18 years. Given brain development continues in young adulthood, and 18-25 year-olds are the most prevalent single occasion risky-drinkers ${ }^{6}$, protecting those under 25 years of age from alcohol advertising should be an important part of efforts to minimise alcohol-related harm. In this respect, the ABAC fails to adequately protect youth. If this scheme is to be retained, it should be expanded to protect young people up to 25 years of age.

The most frequently violated AARB Code provision related to placement, with the vast majority $(88 \%)$ of ads assessed in this study found to be in locations or broadcast at times where youth could be exposed. The ABAC did not include placement provisions during the data collection period, and the new placement provisions that came into effect in 2017 have been criticised for being narrow, unambitious, and substantially flawed ${ }^{23}$. The results of the present study support this view, with a key example being the failure of the new provisions to restrict advertising on public transport vehicles and stops. Around half of 5-17 year-olds use public transport to travel to and from school, compared to just $12 \%$ of adults using public transport for their work commute $^{31}$. Given that $26 \%$ of the ads assessed were located on public transport vehicles or stops, many children are likely to be at high risk of being exposed to alcohol advertising on a daily basis.

Examination of those provisions that were found to be least frequently violated indicated that a substantial minority of these related to ad placement (e.g., broadcasting of alcohol advertisements on radio; broadcasting of ads screened before films rated 18+), which likely reflects the difficulties associated with capturing such ads to submit to the AARB. In addition,

few ads breached provisions relating to the depiction of minors and/or adults under the age of 25 years, which is likely due to these provisions being explicit requirements of the ABAC.

\section{Implications}

Overall, the results suggest the independently-administered AARB Code is a more effective means of capturing problematic alcohol ads and protecting youth from such ads than the industry-led ABAC. The findings provide support for previous critiques of the $\mathrm{ABAC}^{21,23,24,32,33}$ 
and reinforce calls for an independent and mandatory regulatory framework that is appropriately enforced and includes substantial penalties for non-compliance ${ }^{21,23}$. Such a framework should address the numerous flaws of the current regulatory framework by (i) ensuring young people up to 25 years of age are covered in content and placement provisions, (ii) closing loopholes that allow alcohol advertisements to be broadcast during restricted times, and (iii) developing and enforcing stronger placement provisions that cover all forms of marketing. Given the alcohol advertising self-regulatory system in Australia is complaints-driven and there is no active monitoring system ${ }^{21,24}$, alcohol control advocates could look to engage the community to actively monitor and respond to problematic alcohol promotions. Finally, building support for the implementation of other evidence-based, effective alcohol policies, including controls on the price and availability of alcohol, would complement strategies addressing alcohol advertising regulation $^{20}$.

\section{Limitations}

The present study has several limitations. First, analyses were restricted to ads that were available via the AARB data set. These ads had been the subject of formal complaints to the AARB and thus cannot be considered representative of all alcohol promotion in Australia, nor do they necessarily reflect all alcohol ads that have breached either the AARB Code or the ABAC. Although access to these ads provided a unique opportunity to identify where improvements in regulations and/or mandatory regulation may be needed in relation to youth, research that assesses a random sample of alcohol ads is needed to provide results that can be generalised to all alcohol advertising in Australia. Second, as noted above, the data set only included ads that could be captured and substantiated. As ads on certain mediums (e.g., print) are easier to document than those broadcast via other means (e.g., radio), there was an under-representation of the latter.

Third, analyses examining audience reach could not be conducted due to lack of access to such data. This prevented comprehensive assessment of the extent to which young people were exposed to the ads sampled in the present study. Finally, the ads assessed were those captured during the first five years of the AARB Code. During this time, the ABAC did not feature placement provisions and, as such, the ads could not be coded to these provisions. Although the 
results of the present study provide an indication of the lack of comprehensiveness of these new placement provisions, research that explicitly assesses alcohol ads against these recently introduced provisions is needed.

\section{Conclusion}

Among the alcohol ads assessed in the present study, all of which had been the subject of formal complaints to the AARB, most were found to be in violation of the AARB Code's youth-related provisions whereas substantially fewer were in violation of the ABAC. The identified violation rates suggest that self-regulation may be an ineffective means of protecting youth from alcohol advertising. To address this issue, Australian policy makers may consider implementing a mandatory regulatory code that is independent of the alcohol industry.

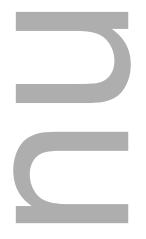

\section{References}

1. Rehm J, Gmel Sr GE, Gmel G, Hasan OS, Imtiaz S, Popova S, et al. The relationship between different dimensions of alcohol use and the burden of disease - an update. Addiction. 2017;112:968-1001.

2. World Health Organization. Global status report on alcohol and health 20182018 [Available from: http://apps.who.int/iris/bitstream/10665/112736/1/9789240692763_eng.pdf?ua=1.

3. Australian Institute of Health and Welfare. Australian Burden of Disease Study 2015: Interactive data on risk factor burden. 2019.

4. Foundation for Alcohol Research \& Education. About alcohol's \$36 billion cost. 2010.

5. Livingston M, Raninen J, Slade T, Swift W, Lloyd B, Dietze P. Understanding trends in Australian alcohol consumption-an age-period-cohort model. Addiction. 2016;111:1590-1598. 6. Australian Institute of Health and Welfare. National Drug Strategy Household Survey 2019: Alcohol chapter - Online data tables. 2020.

7. National Health and Medical Research Council. Australian guidelines to reduce health risks from drinking alcohol. Canberra, Australia: NHMRC.; 2009. 
8. Kaarre O, Kallioniemi E, Könönen M, Tolmunen T, Kekkonen V, Kivimäki P, et al. Heavy alcohol use in adolescence is associated with altered cortical activity: a combined TMSEEG study. Addict Biol. 2018;23:268-280.

9. Heikkinen N, Kärkkäinen O, Laukkanen E, Kekkonen V, Kaarre O, Kivimäki P, et al. Changes in the serum metabolite profile correlate with decreased brain gray matter volume in moderate-to-heavy drinking young adults. Alcohol. 2019;75:89-97.

10. Toumbourou JW, Hemphill SA, McMorris BJ, Catalano RF, Patton GC. Alcohol use and related harms in school students in the USA and Australia. Health Promot Int. 2009;24:373-382. 11. Curtis BL, Lookatch SJ, Ramo DE, McKay JR, Feinn RS, Kranzler HR. Meta-analysis of the association of alcohol-related social media use with alcohol consumption and alcohol-related problems in adolescents and young adults. Alcohol Clin Exp Res. 2018;42:978-986.

12. Jernigan D, Noel J, Landon J, Thornton N, Lobstein T. Alcohol marketing and youth alcohol consumption: a systematic review of longitudinal studies published since 2008 . Addiction. 2017;112:7-20.

13. Lobstein T, Landon J, Thornton N, Jernigan D. The commercial use of digital media to market alcohol products: a narrative review. Addiction. 2017;112:21-27.

14. Kelly B, Baur LA, Bauman AE, King L. Tobacco and alcohol sponsorship of sporting events provide insights about how food and beverage sponsorship may affect children's health. Health Promot J Austr. 2011;22:91-96.

15. Sargent JD, Babor TF. The relationship between exposure to alcohol marketing and underage drinking is causal. Journal of Studies on Alcohol and Drugs. 2020:113-124.

16. Galvan A, Hare TA, Parra CE, Penn J, Voss H, Glover G, et al. Earlier development of the accumbens relative to orbitofrontal cortex might underlie risk-taking behavior in adolescents. J Neurosci. 2006;26:6885-6892.

17. Pechmann C, Levine L, Loughlin S, Leslie F. Impulsive and self-conscious: Adolescents' vulnerability to advertising and promotion. Journal of Public Policy \& Marketing. 2005;24:202221.

18. Romer D. Adolescent risk taking, impulsivity, and brain development: Implications for prevention. Developmental Psychobiology: The Journal of the International Society for Developmental Psychobiology. 2010;52:263-276. 
19. Courtney AL, Casey BJ, Rapuano KM. A neurobiological model of alcohol marketing effects on underage drinking. Journal of Studies on Alcohol and Drugs. 2020:68-80.

20. World Health Organization. Tackling NCDs: "Best buys" and other recommended interventions for the prevention and control of noncommunicable diseases. Geneva: WHO; 2017. Available from: https://apps.who.int/iris/bitstream/handle/10665/259232/WHO-NMH-NVI-17.9eng.pdf;jsessionid=B9FE8A52F4D40958A666B848A2115103? sequence=1.

21. Reeve B. Regulation of alcohol advertising in Australia: Does the ABAC Scheme adequately protect young people from marketing of alcoholic beverages? QUT Law Review. 2018;18:96-123.

22. Pettigrew S, Johnson R, Daube M. Introducing and applying a new Australian alcohol advertising code. Journal of Public Affairs. 2013;13:72-83.

23. Pierce H, Stafford J, Pettigrew S, Kameron C, Keric D, Pratt IS. Regulation of alcohol marketing in Australia: A critical review of the Alcohol Beverages Advertising Code Scheme's new Placement Rules. Drug Alcohol Rev. 2019;38:16-24.

24. Pierce H, Stafford J, Daube M. Developing an alternative alcohol advertising complaint review system: lessons from a world-first public health advocacy initiative. Public Health Research \& Practice. 2017;27.

25. National Preventative Health Taskforce. Australia: The healthiest country by 2020. Canberra: Commonwealth of Australia.; 2009.

26. Arain M, Haque M, Johal L, Mathur P, Nel W, Rais A, et al. Maturation of the adolescent brain. Neuropsychiatr Dis Treat. 2013; 9:449-461.

27. Babor TF, Robaina K, Noel JK, Ritson EB. Vulnerability to alcohol-related problems: a policy brief with implications for the regulation of alcohol marketing. Addiction. 2017;112:94101.

28. The ABAC Scheme Limited. ABAC Adjudication Panel Determination No. 100/20. 2020.

29. Noel JK, Babor TF, Robaina K. Industry self-regulation of alcohol marketing: a systematic review of content and exposure research. Addiction. 2017;112:28-50.

30. Padon AA, Rimal RN, DeJong W, Siegel M, Jernigan D. Assessing youth-appealing content in alcohol advertisements: Application of a Content Appealing to Youth (CAY) index. Health Communication. 2018;33:164-173. 
31. Australian Bureau of Statistics. 2016 Census QuickStats. 2016.

32. Jones SC, Hall D, Munro G. How effective is the revised regulatory code for alcohol advertising in Australia? Drug Alcohol Rev. 2008;27:29-38.

33. Fogarty AS, Chapman S. What should be done about policy on alcohol pricing and promotions? Australian experts' views of policy priorities: a qualitative interview study. BMC Public Health. 2013;13.

Table 1.

Frequency of AARB Code and ABAC provision violations

\begin{tabular}{|c|c|c|c|}
\hline \# provisions violated & Mean (SD) & $\mathrm{N}$ & $\%$ \\
\hline AARB & $3.00(1.77)$ & & \\
\hline 0 & & 35 & 6 \\
\hline 1 & & 87 & 14 \\
\hline 2 & & 157 & 25 \\
\hline 3 & & 126 & 20 \\
\hline 4 & & 113 & 18 \\
\hline $5+$ & & 110 & 18 \\
\hline ABAC & $0.41(0.60)$ & & \\
\hline 0 & & 403 & 64 \\
\hline 1 & & 192 & 31 \\
\hline 2 & & 31 & 5 \\
\hline 3 & & 2 & $<1$ \\
\hline Total & & 628 & 100 \\
\hline
\end{tabular}




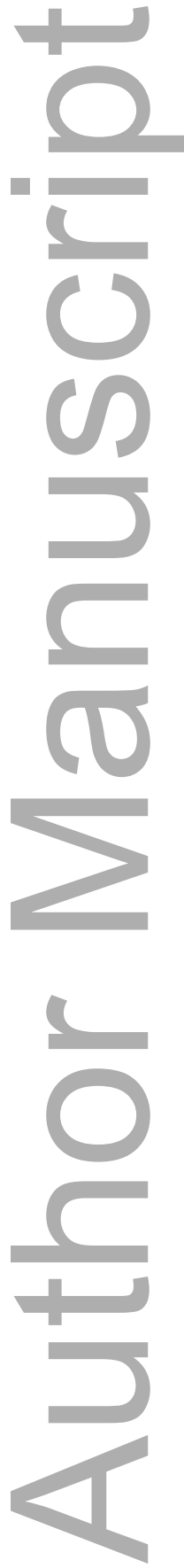

This article is protected by copyright. All rights reserved 
Table 2.

Proportion of ads violating each of the AARB and ABAC provisions relating to youth (in descending order of number of violations)

\begin{tabular}{|c|c|c|}
\hline AARB Provisions & $\mathrm{n}$ & $\%$ \\
\hline $\begin{array}{l}\text { Alcohol Advertisements should not be placed in places or at broadcast times where Young People are exposed or are likely to be } \\
\text { exposed }\end{array}$ & 550 & 88 \\
\hline Alcohol Adyertisements shall not be directed at, or have a strong or evident appeal to, Young People & 302 & 48 \\
\hline Alcohol Advertisements should not be placed in connection with content that appeals to Young People & 195 & 31 \\
\hline Alcohol advertisements shall not associate any Product with youth or youth symbols & 132 & 21 \\
\hline No Alcohol Advertisements shall be placed at any train, tram, bus, or ferry stops & 124 & 20 \\
\hline $\begin{array}{l}\text { Alcohol Advertisements shall not portray Product in the context of, or in relation to, an activity attractive primarily to Young } \\
\text { People }\end{array}$ & 86 & 14 \\
\hline Alcohol Advertisements shall not appear online in connection with content that appeals or is likely to appeal to Young People & 85 & 14 \\
\hline Alcohol Advertisements shall not be broadcast on free-to-air and pay television between 5am and 9pm & 73 & 12 \\
\hline Alcohol Advertisements shall not appear at cultural or sporting events that appeal or are likely to appeal to Young People & 73 & 12 \\
\hline $\begin{array}{l}\text { Labels, graphics, artwork, brand names, packaging, containers and other marketing materials and techniques shall not have an } \\
\text { appearance of special appeal to Young People by way of designs, motifs, cartoon characters or other devices that predominantly }\end{array}$ & 68 & 11 \\
\hline
\end{tabular}

This article is protected by copyright. All rights reserved 
appeal to Young People

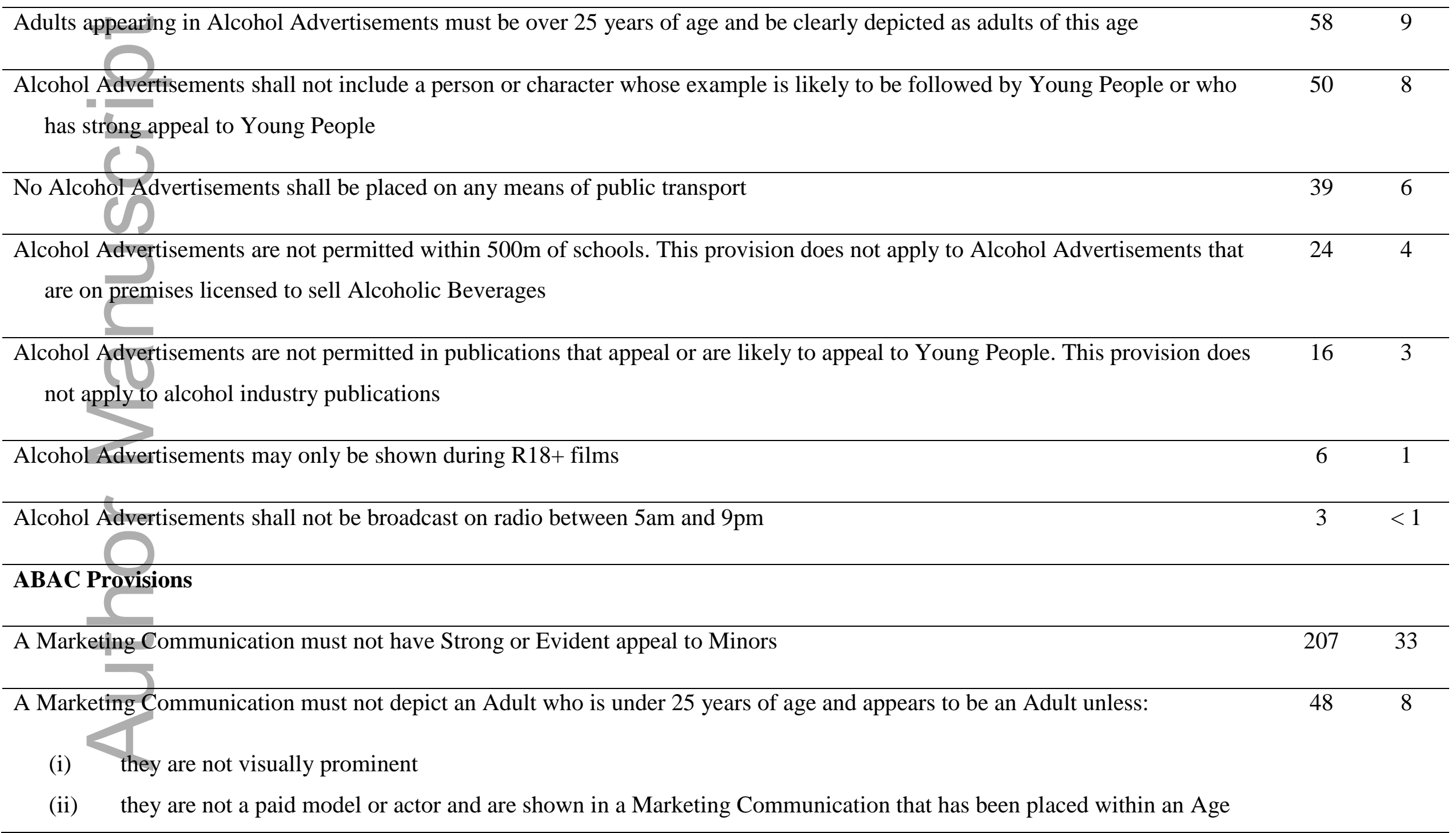

This article is protected by copyright. All rights reserved 


\section{Restricted Environment}

A Marketing Communication must not depict a person who is or appears to be a Minor unless they are shown in an incidental role 5 1

in a natural situation (for example, a family socialising responsibly) and where there is no implication they will consume or serve alcohol

$$
\text { ( }
$$

Note. The definitions of terms within the AARB Code are available at https://alcohol.phaiwa.org.au/alcohol-advertising-review-board.

Definitions of terms within the ABAC are available at www.abac.org.au.

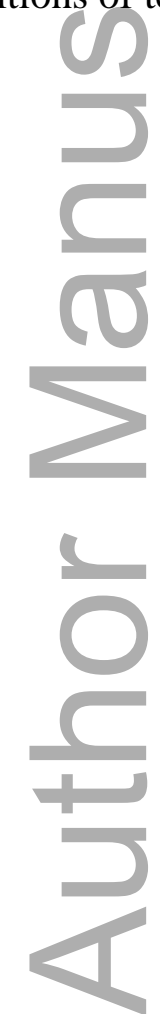

This article is protected by copyright. All rights reserved 


\section{University Library}

\section{- M M N E R VA A gateway to Melbourne's research publications}

Minerva Access is the Institutional Repository of The University of Melbourne

\section{Author/s:}

Jongenelis, MI;Pierce, H;Keric, D;Stafford, J;Jongenelis, G;Pettigrew, S

Title:

Are Australian regulatory codes adequate in scope to protect youth from alcohol advertising?

\section{Date:}

2020-09-15

\section{Citation:}

Jongenelis, M. I., Pierce, H., Keric, D., Stafford, J., Jongenelis, G. \& Pettigrew, S. (2020). Are Australian regulatory codes adequate in scope to protect youth from alcohol advertising?. HEALTH PROMOTION JOURNAL OF AUSTRALIA, 32 (S2), pp.212-217. https://doi.org/10.1002/hpja.410.

Persistent Link:

http://hdl.handle.net/11343/276307 